NASA Technical Memorandum 105299

AIAA-91-3136

\title{
The Design and Performance Estimates for the Propulsion Module for the Booster of a TSTO Vehicle
}

Christopher A. Snyder and Jaime J. Maldonado

Lewis Research Center

Cleveland, Ohio

Prepared for the

Aircraft Design Systems and Operations Meeting

cosponsored by AIAA, AHS, and ASEE

Baltimore, Maryland, September 23-25, 1991

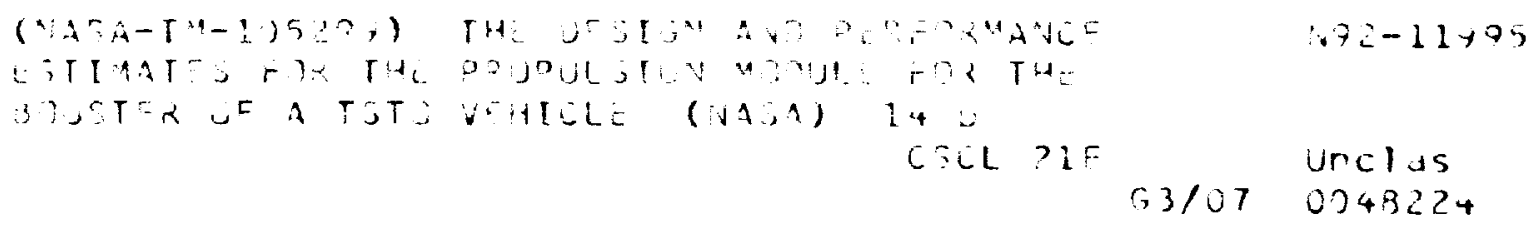




\title{
THE DESIGN AND PERFORMANCE ESTIMATES FOR THE PROPULSION MODULE FOR THE BOOSTER OF A TSTO VEHICLE
}

\author{
Christopher A. Snyder* and Jaime J. Maldonado $\$$ \\ National Aeronautics and Space Administration \\ Lewis Research Center \\ Cleveland, Ohio 44135
}

\begin{abstract}
The Aeropropulsion Analysis Office of the NASA Lewis Research Center is presently studying propulsion systems for possible low-risk replacements for the space shuttle. This study focussed its work on a smaller version of an Air Force two-stage-to-orbit (TSTO) concept called Beta. The NASA concept, Beta II, is to deliver 10,000 pounds to low polar orbit. (The original Beta vehicle is sized to delivered 50,000 pounds.) The booster stage requires a propulsion system for acceleration from take-off to the staging point of Mach 6.5 and about 100,000 feet altitude. The Beta II booster engine module consists of a unique over/under turbine bypass engines/ramjet engine configuration. Performance trade-offs were required to integrate the inlet, turbomachinery, and ramjet design and operation. Discussions about these components and their interactions are included. The methodology and constraints used in the module layout and design will also be discussed. Propulsion system weight and performance will be presented along with preliminary mission study results of vehicle size.
\end{abstract}

\section{INTRODUCTION}

This report details the modifications to the original Beta propulsion module to accommodate the new propulsion system, determining the best turbine engine, the operational regimes of the turbine and ramjet engines and the sizing of these engines. The results of these preliminary studies to define the Beta II propulsion module are presented in this report.

At the start of our two-stage-to-orbit (TSTO) work, several vehicle concepts were reviewed to determine a promising candidate for further study. Desirable features for the study concept were: uses low-risk technology, take-off gross weight under 1

\footnotetext{
* Aerospace Engineer, Member AIAA

$\S$ Aerospace Engineer
}

million pounds, total reusability (nothing thrown away), and "aircraft-like" operational and turnaround characteristics. One vehicle that appeared to embody many of these features was a vehicle concept developed by the Air Force that was initially conceived after their trans-atmospheric vehicle (TAV) studies and was studied further under contract (ref. 1). This concept was called Beta.

The original Beta TSTO vehicle weighed approximately 2 million pounds and delivered a 50,000 pound payload to low polar orbit using low-risk technology. The booster used a combination of turbomachinery, rocket and ramjet propulsion to reach its Mach 8 staging point, as shown in Figure 1. The turbomachinery was designed and sized for a ferry mission of the booster and empty orbiter. The rockets were the main propulsion used for take-off and acceleration to ramjet takeover with the turbomachinery augmenting the rocket thrust. Propellant cross feed from the booster to the orbiter was used to operate the orbiter rocket and insure that the orbiter propellant tanks were full at the staging point.

The vehicle used in our studies was based on the Beta concept. It was reduced in size to deliver 10,000 pounds to low polar orbit. Other differences include reducing the staging point to Mach 6.5 and removal of the propellant cross feed. An overview of the Beta II vehicle design is given in reference 2 .

Initial mission study results were performed using data from the original Beta studies, with the staging Mach number reduced to 6.5. These studies indicated that it would be possible to use only airbreathing propulsion and eliminate the rocket propulsion during the boost stage. This would eliminate the propellant cross feed from the vehicle but require a significant redesign of the propulsion module. This resulted in our baseline Beta II vehicle. The gross take-off weight was approximately 677,000 pounds. The thrust and drag characteristics for this vehicle during its acceleration to the staging point are shown in Figure 2. The vehicle thrust minus drag margin was rather small in the transonic region, but quite adequate over the rest of the flight path.

\footnotetext{
Copyright 1991 by the American Institute of Aeronautics and Astronautics, Inc. No copyright is asserted in the United States under Title 17, U.S. Code. The U.S. Govemment has a royalty-free license to exercise all rights under the copyright claimed herein for Govemmental purposes. All other
rights are reserved by the copyright owner.
} 
From the initial mission study results, it was decided to go to a totally air-breathing booster. The propulsion would be comprised of turbomachinery and ramjets. The study included modifications to the Beta propulsion module to accommodate the new propulsion system, determining the best turbine engine, the operational regimes of the turbine and ramjet engines, and the sizing of the engines. The results of these preliminary studies are presented in this report.

\section{PROPULSION MODULE DESIGN}

The initial Beta propulsion module contained only enough turbomachinery propulsion for a ferry mission of the booster and an empty orbiter. It used mainly rocket propulsion to accelerate the vehicle to the ramjet takeover speed. The original design is shown in Figure 3a. This design includes a combustor splitter plate to separate the turbofans' common afterburner and the ramjet combustor when both were operating. When the turbofans were shut down and closed off, the combustor splitter plate moved to include the turbofans' afterburner as part of the ramjet burner. This increased ramjet burner area significantly, allowing the ramjet to ingest all the inlet airflow and still be fueled stoichiometrically (equivalence ratio $(\phi)$ $=1.0$ ).

There were questions raised about the number and complexity of moving parts in the hot section in the propulsion module. A new preliminary module was conceptually designed and is shown in Figure $3 \mathrm{~b}$. This module design reduces the number of moving parts in the hot exhaust stream by separating the ramjet and turbomachinery flow paths. The combustor splitter plate from the original Beta design increases the ramjet burner area significantly when the turbomachinery is not operating, but had very sharp turning angles and a lot of moving parts in the center of the hot gas path. For these reasons, the combustor splitter plate was not considered near term and was therefore removed. The inlet air splitter was also moved from the supersonic inlet section (in the original design) to the subsonic diffuser. It was felt that this would result in better inlet performance.

The change from rocket to air-breathing propulsion increased the size of the propulsion module in relation to the rest of the vehicle. This hurt vehicle aerodynamics, especially in the transonic region where the vehicle has its minimum thrust minus drag margin. To reduce this penalty, effort was concentrated on maximizing transonic thrust and minimizing the propulsion module size, while still having sufficient airbreathing propulsion for the mission.

\section{METHOD OF ANALYSIS}

The initial propulsion studies included screening studies of different cycles and cycle parameters. For the turbine engines, design point overall pressure ratios (OPRs) of 15, 20, and 25, and maximum turbine inlet temperatures of 3360 and $3560{ }^{\circ} \mathrm{R}$ were analyzed. Parameters investigated for the ramjet were Mach number and altitude limits, ramjet burner to inlet capture area ratio, inlet pressure recovery, and cooling requirements.

For the initial screening studies, inlet performance from the initial Beta TSTO vehicle was used. For nozzle performance, a gross thrust coefficient of 0.98 was used. As the vehicle and propulsion system became better defined, inlet and nozzle performances for the new design were calculated in-house (ref. 3).

The NNEP89 computer code was used to calculate turbomachinery performance (ref. 4\&5). NNEP89 performs one-dimensional, steady state, thermodynamic analysis of turbine engine cycles. Fan and compressor aerodynamics were calculated using a parametric map generating program (ref. 6). Turbine aerodynamics were obtained from advanced turbine designs compatible with the temperature and cooling requirements used in the studies. The engine performance was computed assuming maximum afterburner augmentation. A standard hydrocarbon fuel, JP4, fueled the turbomachinery.

Program RAMSCRAM was used to calculate ramjet performance (ref. 7). RAMSCRAM performs one-dimensional thermodynamic analysis, including equilibrium chemistry effects, for a ramjet or scramjet duct. As the program steps through the engine, efficiency factors are input for flow path losses. A constant area burner and a combustion efficiency of 97.5 percent were assumed, using the methods described in reference 7 . The program will automatically determine the loss in momentum due to the heat release in the combustor. The ramjet was fueled with hydrogen. The fuel to air ratio was varied to achieve maximum net thrust, which usually turned out to be stoichiometric.

\section{INITLAL TURBOMACHINERY STUDIES}

The engine cycles included in the initial screening were turbojet, turbine bypass engine (TBE), and turbofan engines. Each engine was designed at sea level static conditions for 700 pounds per second corrected airflow. Designing each engine with the same airflow would give each engine roughly the same frontal area and indicate which engine has the highest 
thrust per cross sectional area. Increasing turbomachinery thrust per frontal area could reduce module cross sectional area or increase area available for the ramjet. The engines were then flown over the flight path shown in Figure 4, which is typical of the flight profile flown by the Beta II vehicle. Initial studies performed varying turbine engine thrust, specific fuel consumption, and engine weight indicated that the vehicle size was the most sensitive to changes in thrust, especially in the transonic region. Therefore, the optimum engine for initial screening purposes was judged primarily on transonic thrust.

\section{Turbojet Performance}

The thrust versus Mach number for turbojets at OPRs of 15,20 , and 25 at a turbine inlet temperature of $3560^{\circ} \mathrm{R}$ is shown in Figure 5. The drop in thrust at Mach 1.2 was caused by the vehicle gaining altitude in order to dive through the critical thrust minus drag point. Increasing turbine inlet temperature increased thrust, as expected. The thrust versus Mach number trends at $3360^{\circ} \mathrm{R}$ were similar to curves for $3560^{\circ} \mathrm{R}$ at OPRs of 15 to 25 . Engine performance with maximum augmentation tends to obscure the differences caused by the engine OPR. Although all turbojets had about the same thrust in the range of interest, the turbojet with an OPR of 25 and a turbine inlet temperature of $3560^{\circ} \mathrm{R}$ had slightly better thrust transonically and the highest thrust at take-off.

\section{Turbine Bypass Engine (TBE) Performance}

For the single spool TBE, 20 percent of the core airflow was bypassed around the turbine at design point and mixed with the core airflow after the turbine. The thrust versus Mach number for the TBE at OPRs of 15 , 20 , and 25 at a turbine inlet temperature of $3560^{\circ} \mathrm{R}$ is shown in Figure 6. The thrust versus Mach number trends at $3360^{\circ} \mathrm{R}$ were similar to curves for $3560^{\circ} \mathrm{R}$ at OPRs of 15 to 25. The drop in thrust at Mach 1.2 was caused by altitude effects. Increasing turbine inlet temperature increased thrust for this engine as it did for the turbojet. The TBE with the highest thrust in the range of interest had an OPR of 25 and a turbine inlet temperature of $3560^{\circ} \mathrm{R}$.

\section{Turbofan Performance}

The turbofan engine was a two-spool, mixedflow engine. At design point, fan pressure ratios (FPRs) of 2.0 and 3.0 were chosen and engine bypass ratios were varied to match the total pressures of the bypass and core airflows. Net thrust versus Mach number at a maximum turbine inlet temperature of $3560^{\circ} \mathrm{R}$ at OPRs of 15,20 and 25 are shown in Figures 7 and 8 for FPRs of 3.0 and 2.0, respectively. The curves for each turbofan with the same FPR but different OPRs are very similar. Higher fan pressure ratios reduced the bypass ratio, giving higher thrust over the flight range. For the turbofan with a FPR of 3.0 , the engine with an OPR of 15 and a maximum turbine inlet temperature of $3560^{\circ} \mathrm{R}$ had the highest thrust in the Mach 1 to 1.5 region. This was also true for the turbofan with a FPR of 2.0 .

\section{Optimum Turbomachinery Cycle}

Using uninstalled thrust in the Mach 1 to 1.5 region as the criterion for the optimum cycle, the optimum turbojet, TBE and turbofan engines were compared. The thrust of the optimum turbojet, TBE and the two turbofans are shown in Figure 9. The engine with the highest thrust in the Mach 1 to 1.5 region from the cycles studied was the turbojet with an OPR of 25 and a maximum turbine inlet temperature of $3560^{\circ} \mathrm{R}$. The TBE and the turbofan with a FPR of 3.0 were also very close in performance to the turbojet in the Mach 1 to 1.5 range, but the turbojet was chosen because it also had highest take-off thrust.

\section{INITIAL RAMJET STUDIES}

The next step was to determine the ramjet size necessary for the mission. The baseline Beta II vehicle was 30 percent smaller in size than the original Beta concept. If the propulsion module to vehicle size ratio was maintained, the propulsion module size would also be reduced about 30 percent. After the amount of turbojet propulsion required transonically was added to the module, the ramjet bumer cross sectional to inlet capture area ratio was about 0.3. The original Beta vehicle propulsion module had a large ramjet bumer cross-sectional to inlet capture area ratio (about 0.75 ). Ramjet parametric studies were run to determine the actual ramjet area and its operational limits. The ramjet performance trades looked at included: Mach and altitude limits to ramjet operation, altitude effects, burner-to-inlet area ratios effects, inlet recovery effects, bleeding excess air effects at Mach 3 (a possible thrust critical point), and the effects of some inlet air (at speeds above Mach 3) being used for cooling.

\section{Mach and Altitude Limits}

To determine the Mach number/altitude limits for the Beta II vehicle, the maximum internal pressure of the ramjet was calculated along the initial flight path of the baseline vehicle. There was a question whether it could stage at Mach 6.5 or the staging Mach number would have to be reduced to 6 . Increasing the staging Mach number reduced the orbiter and total vehicle size. It also improved the integration of the two vehicles. 
The vehicle accelerated along the vehicle structural limit of 1500 pounds per square foot dynamic pressure up to Mach 6.0, and then began a pull up maneuver to a lower dynamic pressure to reach the Mach 6.5, 100,000 feet staging point. Mach 6.5 was chosen to be the staging Mach number because it was judged to be the maximum Mach number for low-risk ramjet operation and passive cooling of the booster vehicle. This calculation would indicate if internal pressures were too high and the flight path would have to modified.

The Beta II flight profile is shown in Figure 10. The flight profile limits for 1500 pounds per square foot dynamic pressure (vehicle structural limit), and 10 and 15 atmospheres engine maximum internal pressure limits are also included on the figure. The vehicle would have to fly above the corresponding dynamic and internal pressure curves to not exceed these limits. The internal pressure is always less than the maximum of 15 atmospheres. To limit the maximum internal pressure to 10 atmospheres, the vehicle would have to increase its flight altitude above Mach 5 . Because of the pull up at Mach 6, the internal pressure at Mach 6.5 is $1 / 3$ less than at Mach 6, while the internal temperature is only slightly higher (3.3 percent). This suggests that Mach 6.5 is a less severe heating condition than Mach 6. Assuming that the vehicle could thermally and structurally handle the Mach 6 condition, the staging point could be extended to Mach 6.5. This confirmed using the baseline flight path until engine and vehicle heat loads could be included.

\section{Altitude Effects on Ramjet Performance}

To reduce the number of ramjet calculations for the parametric engine and trajectory optimization studies, ramjet performance was calculated at different altitudes (constant levels of dynamic pressure of 500 , 1000 , and 1500 pounds per square foot) to determine if uninstalled net thrust divided by dynamic pressure was only a function of Mach number. The ramjet burner to inlet capture area ratio was assumed to be 0.75 , the equivalence ratio was 1.0 , and the nozzle exit area was set equal to the inlet capture area. The results from these calculations are shown in Figure 11.

Net thrust divided by dynamic pressure is almost only a function of Mach number. Altitude effects were always less than 4 percent. Subsequent ramjet calculations for the initial studies were only performed at a dynamic pressure of 1500 pounds per square foot, the approximate flight profile of the vehicle for most of the mission.

\section{Ramiet Bumer to Inlet Capture Area Ratio}

After the approximate module area required by

the turbomachinery was estimated, it was also necessary to determine the minimum ramjet burner area required to do the mission. The effects of different ramjet burner to inlet capture area ratios were calculated two ways. First, what burner size was required for a given burner entrance Mach number, and second, the effect of the burner area on net thrust. For both calculations, inlet flow and recovery were assumed constant. For the burner area effect on net thrust, the equivalence ratio was reduced from stoichiometric, if necessary, to pass the required inlet flow. (The airflow was limited by choking at the burner exit for some conditions.)

Figure 12 is a plot of the ratio of ramjet bumer to inlet capture area over the flight Mach number range, assuming certain bumer entrance Mach numbers. As can be seen, the burner area increased significantly at lower burner entrance Mach numbers. Lower burner entrance Mach numbers reduced the momentum loss from the heat addition from combustion in the burner, but increased ramjet bumer area. If the ramjet burner area was too small or the entrance Mach number was high enough, the flow at the burner exit could choke. Choking would limit the amount of fuel that could be added to the ramjet and would limit thrust.

Figure 13 is a plot of net thrust divided by dynamic pressure over the flight Mach number at different values of the ramjet burner to inlet capture area ratio. Like Figure 12, this shows the effects of different ramjet burner areas, but in a different way. At large bumer to inlet capture area ratios or high flight Mach numbers, the ramjet is inlet airflow limited. Burner entrance Mach numbers and momentum losses were low and have little effect on net thrust. With smaller burner to inlet capture area ratios at lower flight Mach numbers, the ramjet is burner area limited. Burner entrance Mach numbers, momentum losses, and the effects on net thrust were higher. For the smallest bumer to inlet capture area ratio, below Mach 4, the fuel to air ratio had to be reduced significantly, with a corresponding decrease in net thrust to pass the required flow. This study indicated that the propulsion module should be enlarged from the initial 0.3 burner to inlet capture area ratio determined from the initial turbomachinery studies to approximately 0.375 . This ratio was used for subsequent calculations.

\section{Inlet Pressure Recovery Effects}

The effect of reductions in the inlet pressure recovery over the flight path is shown in Figure 14. Inlet pressure recovery can have significant effects on the ramjet performance. Initial inlet performance was reduced 10 and 20 percent with no reduction in airflow captured and the effect on net thrust was calculated. The burner to inlet capture area ratio was 0.375 . Inlet 
recovery losses had little effect at the higher Mach numbers, but the losses were substantial at lower Mach numbers. The loss in thrust at the lower Mach numbers was a combination of the lower pressure and the reduction in fuel to air ratio required to keep the flow from choking in the ramjet bumer. Mach 3 is the point at which the turbomachinery shuts down and all vehicle thrust is produced by the ramjets. The results of this study indicate that ramjet bumer area, inlet flow and inlet pressure ratio were critical factors at Mach 3 for the ramjet.

\section{Airflow Reduction Effects at Mach 3}

Some initial in-house inlet performance estimates indicated higher Mach 3 inlet airflow than the ramjet could handle and burn stoichiometrically. Reducing the equivalence ratio to pass this airflow would reduce ramjet thrust substantially. Because of the perceived possible thrust problem at Mach 3, additional performance was calculated reducing ramjet airflow to get the fuel to air ratio back to stoichiomctric. Figure 15 shows the effect of reducing ramjet airflow on the net thrust at Mach 3. The airflow was reduced by reducing inlet capture area, or bleeding excess airflow and dumping it overboard with a total loss of inlet momentum. This would indicate the limits of performance for airflow reduction.

As the airflow going through the burner is decreased, and the ramjet can be fueled at conditions closer to stoichiometric, performance is constant or increasing. Once the ramjet reaches the point which it can fueled stoichiometrically, any further reduction in the airflow has a significant decrease in thrust. This suggests that reducing the airflow at Mach 3 to reach stoichiometric fueled conditions, would not be very harmful to thrust.

\section{Cooling Bleed Effects Above Mach 3}

If some of the inlet airflow is needed for cooling some of the engine hot section, how that air is exhausted is very important to the vehicle. Ramjet performance was estimated to simulate the use of some of the inlet airflow for cooling and the effect it had on engine performance and the vehicle. The cooling airflow was then either added back to the nozzle flow and recover all of its momentum or dumped overboard with no momentum recovery.

Figures 16 and 17 show the relative effects on net thrust and specific impulse, respectively, over the flight path if 30 percent of the inlet airflow was used for cooling. When the cooling flow is added back in the nozzle, a substantial amount of momentum is recovered, otherwise there is a significant penalty to the cycle performance. For the baseline vehicle, vehicle weight growth was about 7500 pounds or about 1.1 percent, if the cooling air was added back in the nozzle. If the cooling air was dumped overboard, the vehicle weight grew 13.1 percent to 765,000 pounds. This was a substantial penalty on a vehicle with a high thrust minus drag margin during the cooling bleed. If the vehicle did not have such a large thrust minus drag margin, the increase in vehicle growth would have been much greater.

\section{LATER STUDIES}

After the initial studies, the initial turbojet engine was changed to a candidate high-speed research (HSR) engine being studied for the high-speed civil transport (HSCT). It would reduce the development costs of the Beta II turbomachinery to use the same engine for Beta II and the HSCT. Of the HSCT candidate engines, the TBE was chosen because it was closest in design to the initial study results. From optimization of the turbine bypass flow, it was found the HSCT TBE actually had higher thrust in the transonic region than the initial turbojet engine. But the TBE would have to be throttled back extensively to reach the Mach 3 turbomachinery shut down point and not exceed engine temperature/stress limits. The added performance and airflow of operating the TBE up to Mach 3 as opposed to shutting it down earlier were very important to reduce inlet spillage.

The next step in the iteration was to integrate turbomachinery and ramjet airflow and nozzle area requirements with inlet and nozzle performance to conver uninstalled performance to propulsion module installed performance. This effort included calculating airflows for the TBE and ramjet flow paths. The initial and final airflows for the TBEs and ramjet, per propulsion module, are shown in Figure 18. This airflow schedule was used to calculate the actual inlet and nozzle performance and drags. All studies from this point onward used NASA in-house calculated inlet, engine and nozzle performance.

The first integration of the inlet, engine, and nozzle components indicated thrust deficiencies in the transonic region. The airflow schedule for optimum engine performance required significant amounts of spillage below Mach 3, and caused large nozzle boattail drags transonically. Since the TBEs were already running at maximum airflow conditions, (without overspeeding the engine), the airflow through the ramjet would have to be increased. Further studies were conducted to better integrate the inlet, engine and nozzle components for improved performance. The studies included reduction of the ramjet equivalence ratio over part of the flight regime and adding an inlet 
bypass system. Adding the inlet bypass system is discussed in reference 3 and will not be discussed here.

\section{Bamjet Equivalence Ratio ( $\phi$ ) and Airflow}

In the transonic region, the turbomachinery is producing the major portion of vehicle thrust. The ramjet is also operating in this region and its airflow was chosen to maximize ramjet thrust. Figures 19 and 20 show the effect of ramjet equivalence ratio on net uninstalled thrust and airflow, respectively. As the ramjet equivalence ratio was varied, the airflow also varied as required to choke the ramjet at the burner exit. As can be seen, as the equivalence ratio is decreased, ramjet airflow increased, often dramatically. Reducing the equivalence ratio from 1 to 0.6 reduced thrust from 10 to 20 percent, with a 10 percent increase in airflow. From these results, it was decided to operate the ramjet at an equivalence ratio of 0.6 . This equivalence ratio may not be the optimum, but this change and others in reference 3 reduced inlet and nozzle losses sufficiently to fulfill the mission requirement. Further studies should be performed to determine the actual optimum ramjet equivalence ratio.

\section{FINAL PROPULSION SYSTEM PERFORMANCE}

The propulsion module layout from this study is shown in Figure 21. There are two propulsion modules on the vehicle. Each module contains four-520 pounds per second of corrected airflow TBEs, running with stoichiometric afterbumers. Each ramjet has a burner area of 111.2 square feet. The inlet capture area is 189.5 square feet, with a module maximum cross sectional area of 290 square feet.

\section{TBE and Ramjet Performance}

Present installed performance, including inlet and nozzle drags, is shown in Figures 22 and 23 for the TBEs, and Figures 24 and 25 for the ramjet. The graphs are the performance for each module and include operation of the inlet bypass bleed system. The inlet bypass bleed system drags are included in the inlet losses. All inlet and nozzle additive and spillage drags are assigned to the TBE and ramjet system according to the relative thrust that each is producing.

As is shown in Figures 24 and 25 , the ramjet is burning and producing some installed thrust subsonically. The ramjet did have air flowing during subsonic flight to reduce inlet and nozzle drag. A minor amount of fuel was added (equivalence ratio ranged from 0.10 to 0.40 ) to maximize the uninstalled ramjet thrust, but these calculations did not include the inlet and nozzle losses. These losses were added later to the TBE and ramjet engines, depending on how much uninstalled thrust each engine was producing. If the inlet and nozzle losses were assigned on the basis of engine airflow, TBE installed performance would have been higher and the ramjet performance lower.

\section{Propulsion Module Weight}

Weight for the TBE was determined using the WATE2 subroutines of NNEP89 (ref. 8). The weights for the other propulsion items were determined by the Boeing Space and Defense Group under contract F33615-86-C-3004. A weight breakdown for the propulsion module is given in the table.

\section{CONCLUDING REMARKS}

Preliminary turbomachinery and ramjet performance was calculated to determine the optimum configuration for an air-breathing propulsion module for the booster of a TSTO vehicle. The transonic propulsion performance is critical. Although preliminary studies indicated that turbojet engines were the optimum cycle, other factors lead to the selection of a HSCT candidate engine, the TBE, for the turbomachinery. Mach 6.5, 100,000 feet altitude, was confirmed as a viable staging point. Ramjet burner to inlet capture area ratios greater than 0.3 were required to maintain sufficient ramjet thrust at Mach 3, when the turbomachinery shuts down. For small ramjet burner to inlet capture ratios, reducing inlet airflow at Mach 3 had little effect on ramjet thrust. By increasing inlet bleed and reducing ramjet airflow, the ramjet equivalence ratio can be increased closer to 1 , offsetting the increase in inlet drag by increasing ramjet thrust. Once the equivalence ratio reached 1 , increasing inlet bleed caused large reductions in thrust. Ramjet performance is more sensitive to inlet performance at lower Mach numbers than at the highest Mach numbers. If some of the ramjet airflow is used for engine or vehicle cooling, it could have significant effects on vehicle size. If the pressure loss for the cooling airflow was small, the airflow might be exhausted in the ramjet nozzle, with only minor performance penalties; otherwise the penalties could be significant. Inlet and propulsion airflow matching was essential to maximize system performance. Ramjet equivalence ratio was reduced transonically to increase propulsion module airflow and total thrust.

\section{References}

1. Paris, S. W.; Wetzel, E. D.; Meadowcroft, E. T.; Weldon, V. A.; Kotker, D. J.; Williams, D. P.: Research Vehicle Configurations for Hypervelocity Vehicle Technology. WRDC-TR-90-3003, Volumes I and II, April 1990. 
2. Plencner, R. M.: Overview of the Beta II TwoStage-To-Orbit Vehicle Design. AIAA Paper 913175, 1991.

3. Midea, A. C.: Mach 6.5 Air Induction System Design for the Beta II Two-Stage-to-Orbit Booster Vehicle. AIAA Paper 91-3196, 1991.

4. Plencner, R. M.; Snyder, C. A.: The Navy/NASA Engine Program (NNEP89) - A User's Manual. NASA TM-105186, 1991.

5. Fishbach, L. H.; Gordon, S.: NNEPEQ - Chemical Equilibrium Version of the Navy/NASA Engine Program. NASA TM - 100851, 1988.

6. Converse, G. L.; Giffin, R. G.: Extended Parametric Representation of Compressor, Fans and Turbines Volume I - CMGEN User's Manual. NASA CR - 174645, March 1984.

7. Burkardt, L. A.; Franciscus, L. C.: RAMSCRAM A Flexible Ramjet/Scramjet Engine Simulation Program. NASA TM - 102451, 1990.

8. Onat, E.; Klees, G. W.: A Method to Estimate Weight and Dimensions of Large and Small Gas Turbine Engines. NASA CR-159481, 1984.

\begin{tabular}{|lr|}
\hline Propulsion System & Weight (lbs) \\
\hline \hline Turbomachinery & \\
Engines & \\
(8 TBEs, 4 per module) & 48270 \\
Inlet Interface & 8060 \\
Nozzle Interface & 4710 \\
Engine Supports & 740 \\
Thermal Protection & 1500 \\
Total & 63280 \\
\hline \hline Ramjet & \\
Engines & \\
(2 engines, 1 per module) & 71610 \\
Propellant Management & 1650 \\
Total & 73260 \\
\hline \hline Total & \\
(8 TBEs, 2 Ramjets) & 136540 \\
\hline
\end{tabular}

Table. Beta II Propulsion Module Weights

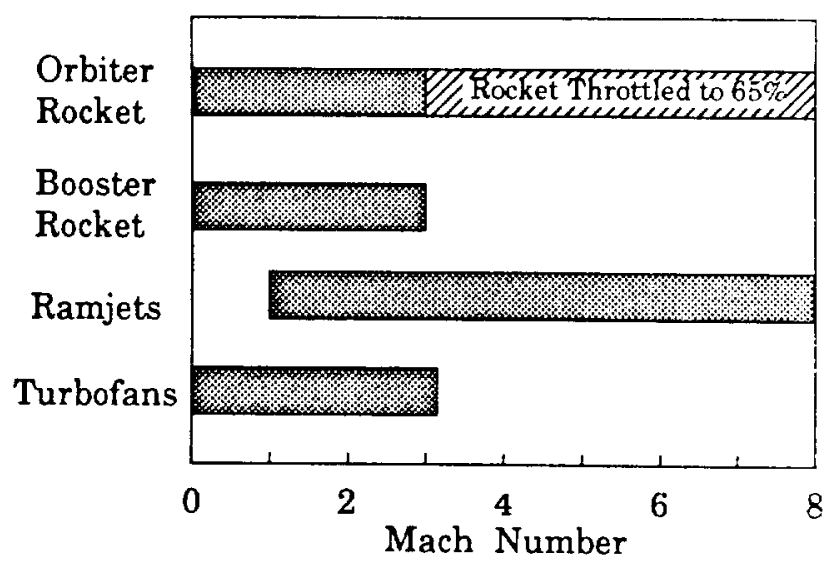

Figure 1. Beta Propulsion Operation

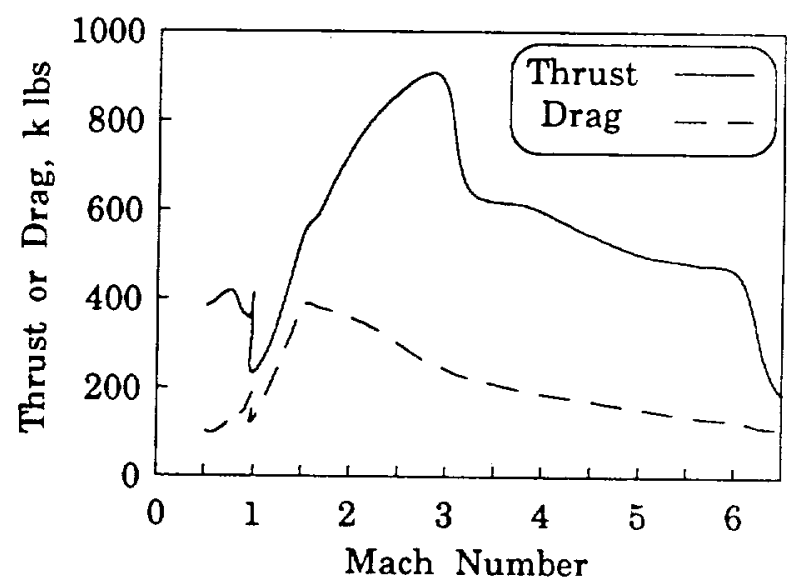

Figure 2. Beta II Baseline Vehicle Thrust and Drag Profiles 


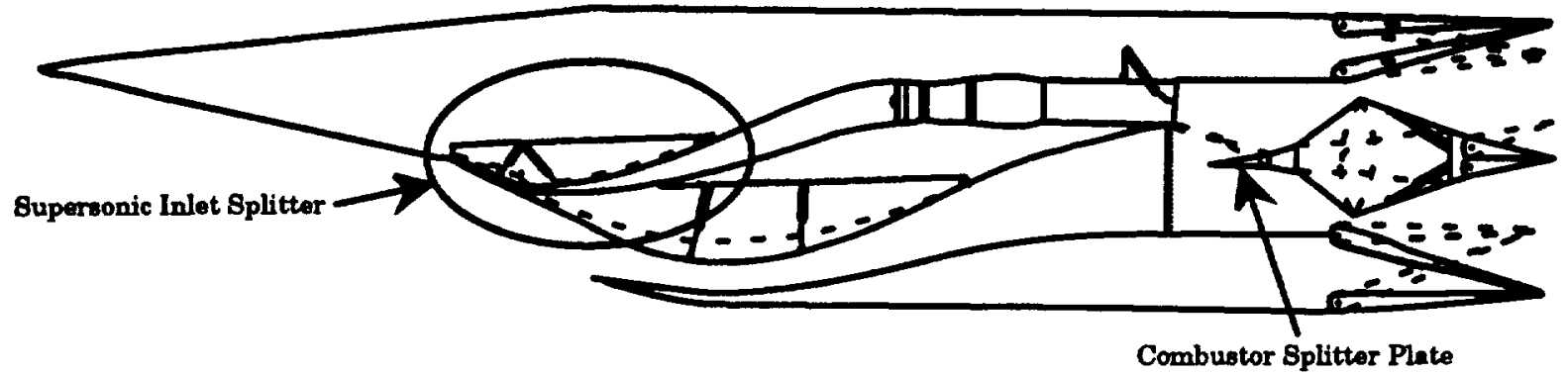

Figure 3a. Beta Propulsion Module

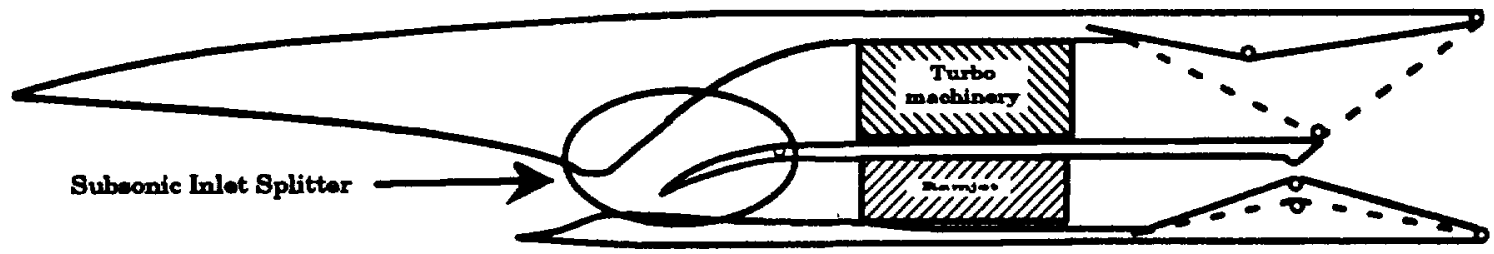

Figure 3b. Beta II Propulsion Module

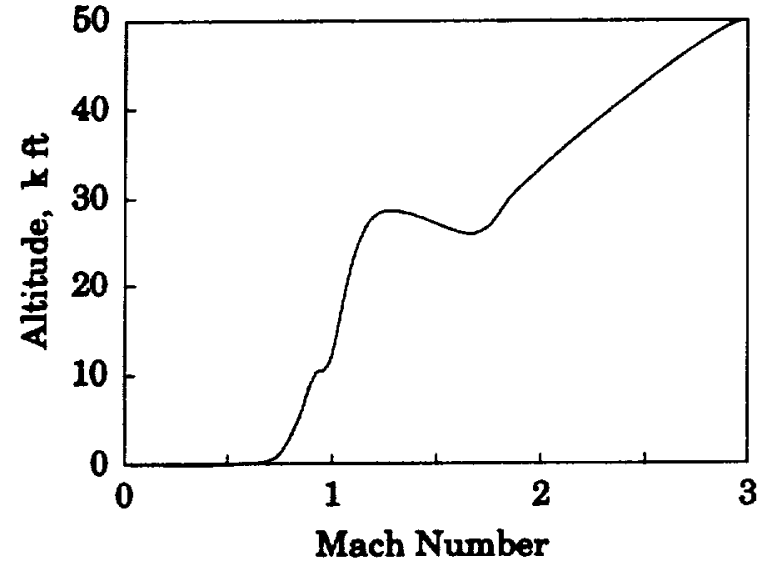

Figure 4. Turbomachinery Flight Path

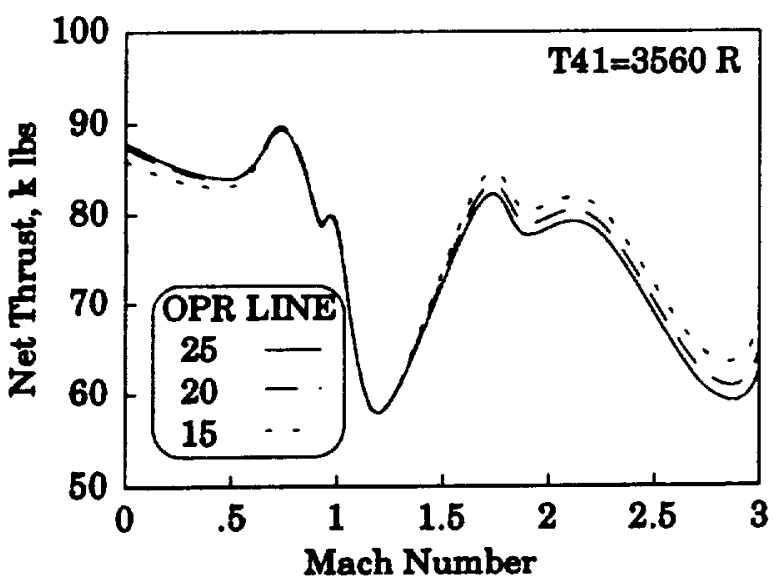

Figure 6. OPR Effects on TBE Thrust

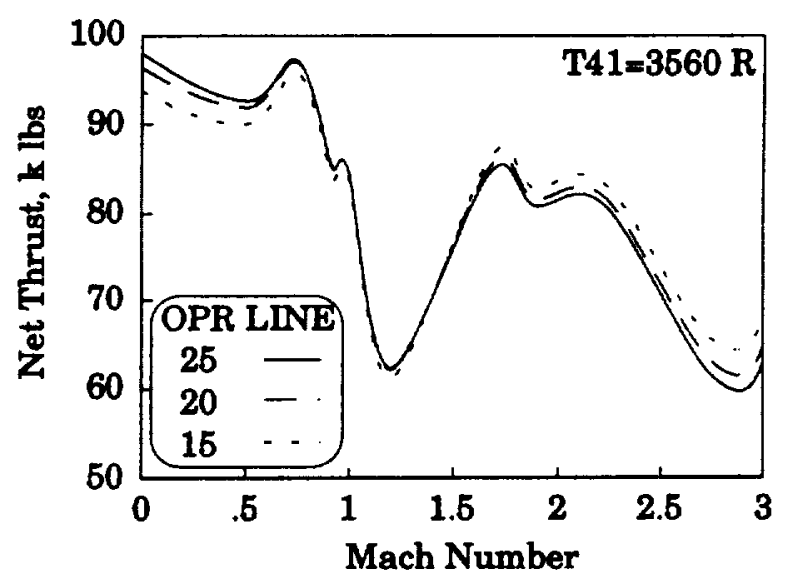

Figure 5. OPR Effects on Turbojet Thrust

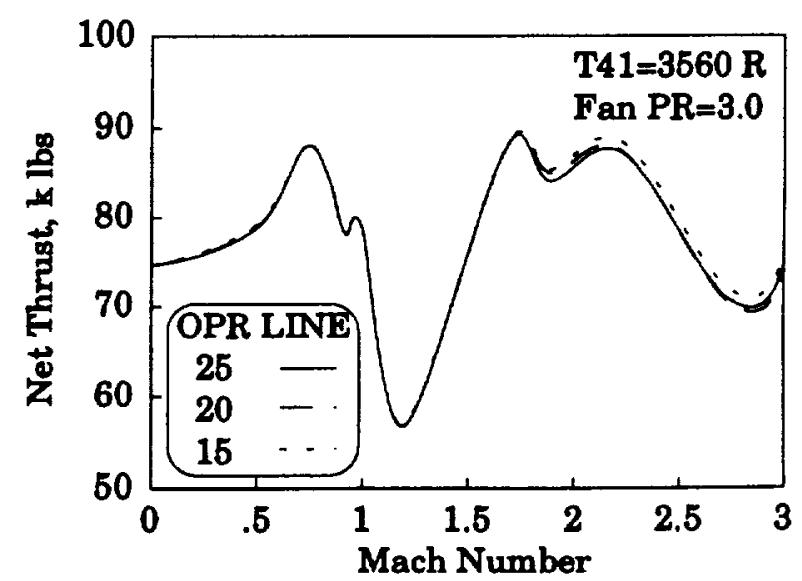

Figure 7. OPR Effects on Turbofan Thrust 


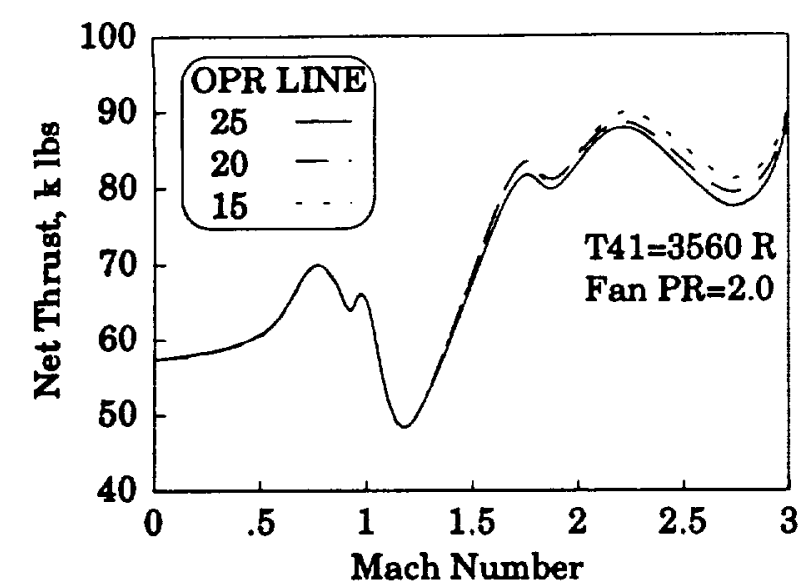

Figure 8. OPR Effects on Turbofan Thrust

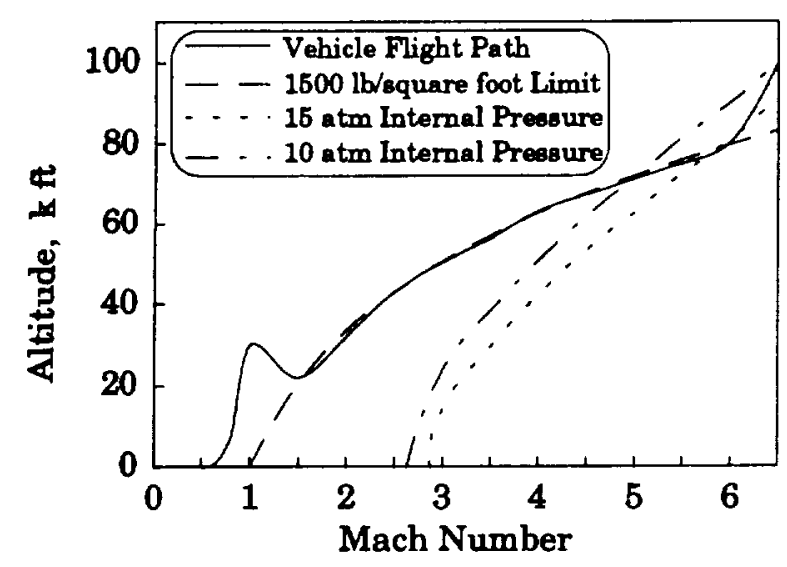

Figure 10. Beta II Trajectory and Limits

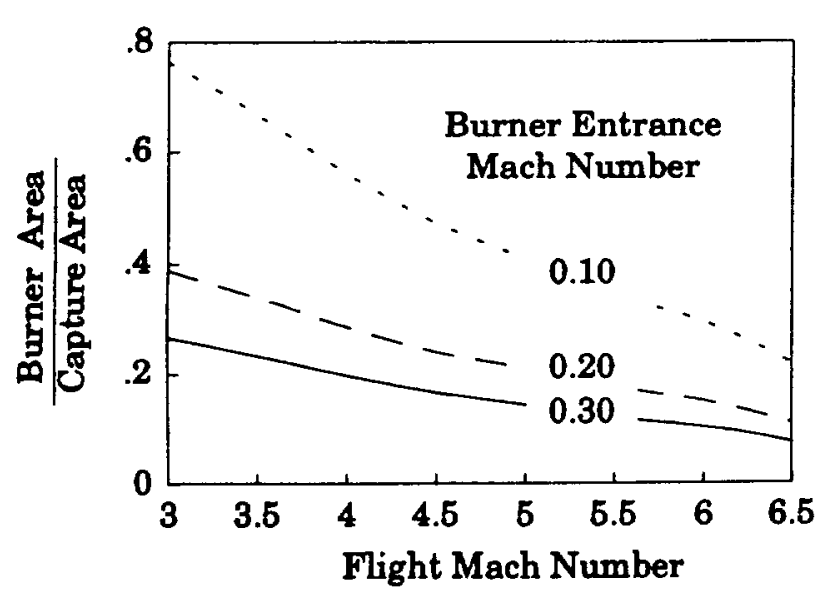

Figure 12. Entrance Mach Number Effect on Ramjet Burner Area

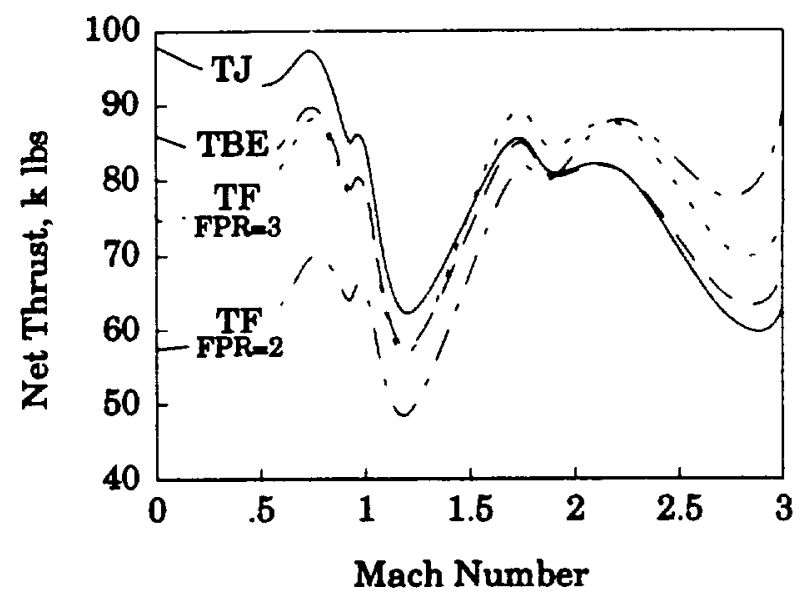

Figure 9. Comparison of Optimum Turbojet, TBE and Turbofan Engines

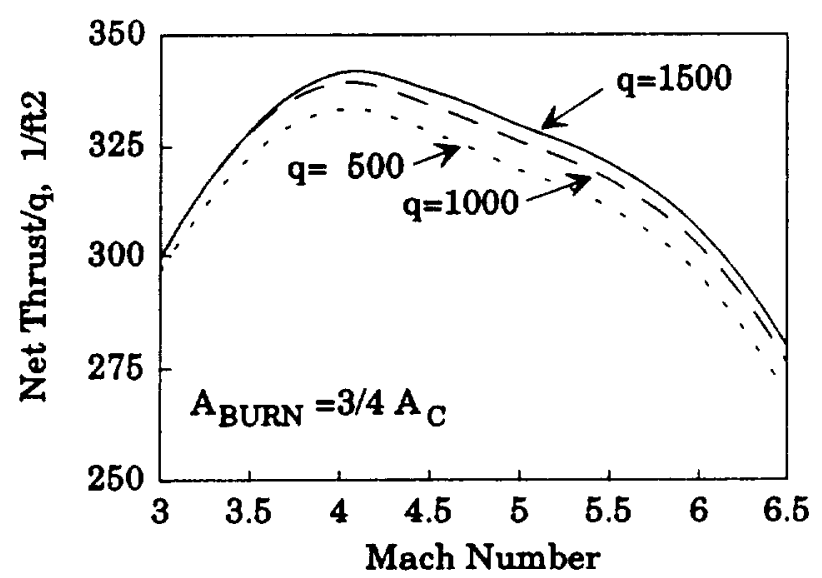

Figure 11. Altitude Effects on Ramjet Performance

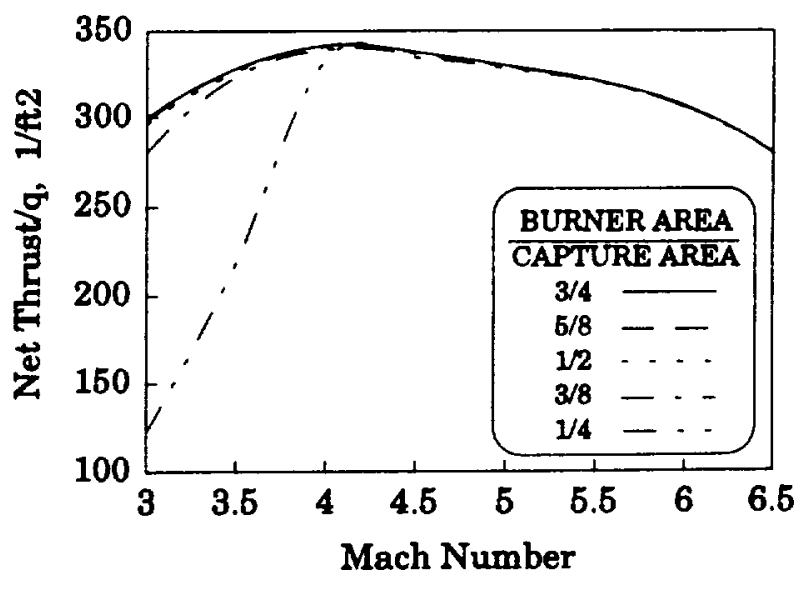

Figure 13. Effect of Ramjet Burner Area on Net Thrust 


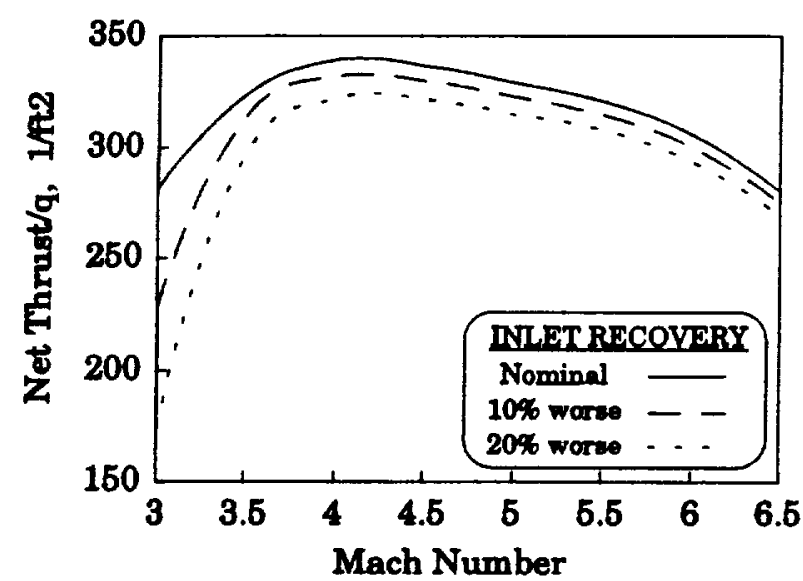

Figure 14. Effect of Inlet Recovery Loss on Net Thrust

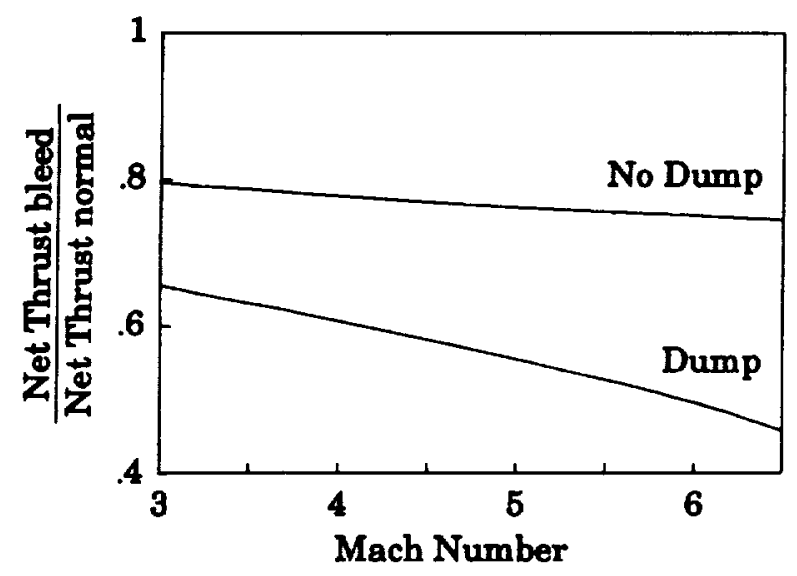

Figure 16. Cooling Bleed Effects on Net Thrust

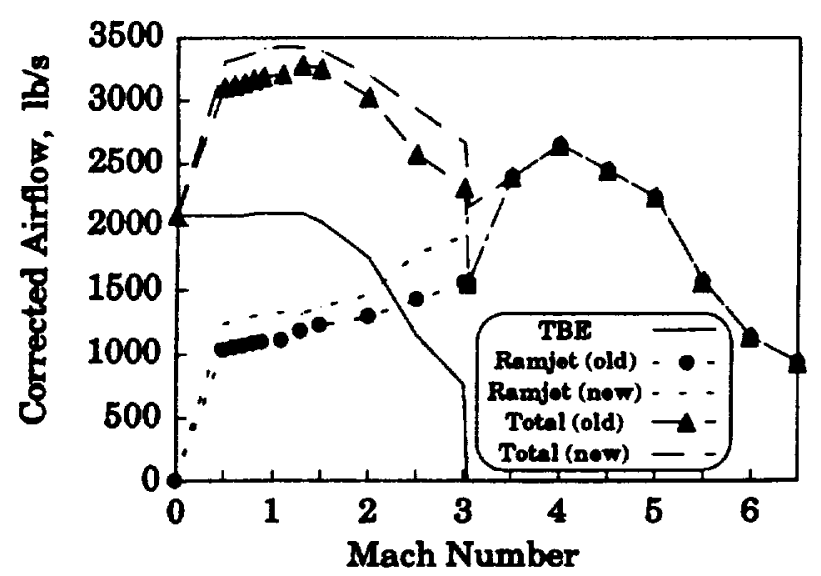

Figure 18. Beta II Propulsion Airflow

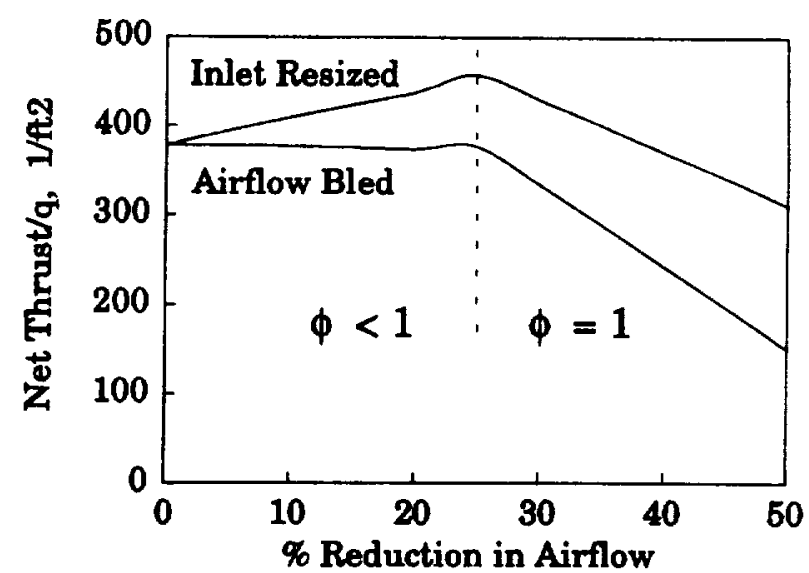

Figure 15. Effect of Airflow Reduction on Net Thrust at Mach 3

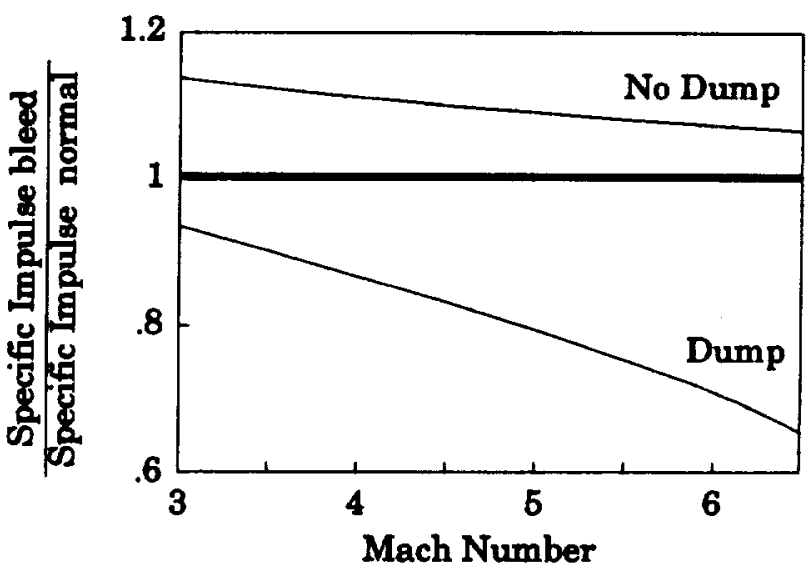

Figure 17. Cooling Bleed Effects on Specific Impulse

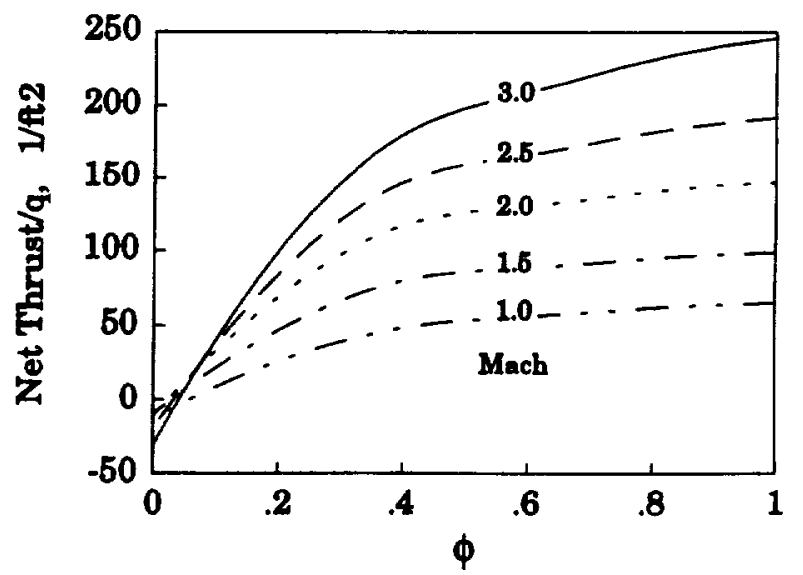

Figure 19. Effect of $\phi$ on Net Thrust 


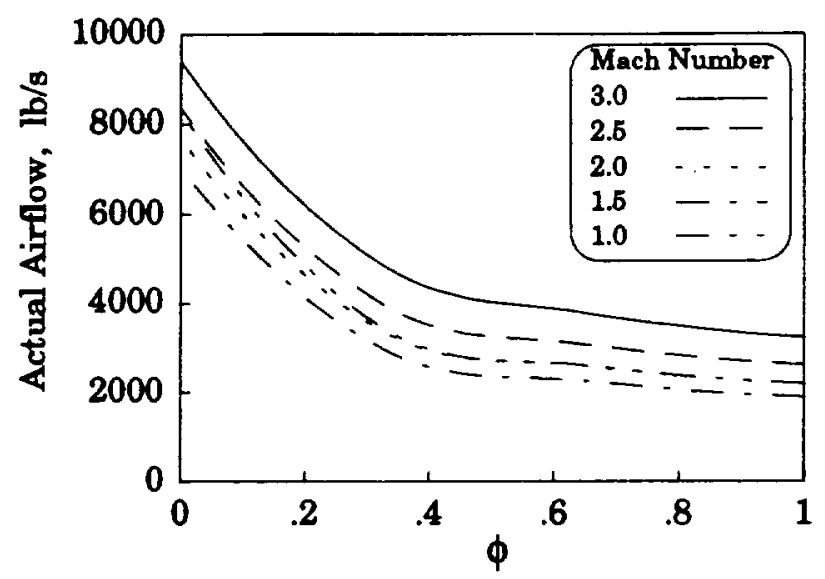

Figure 20. Effect of $\phi$ on Airflow

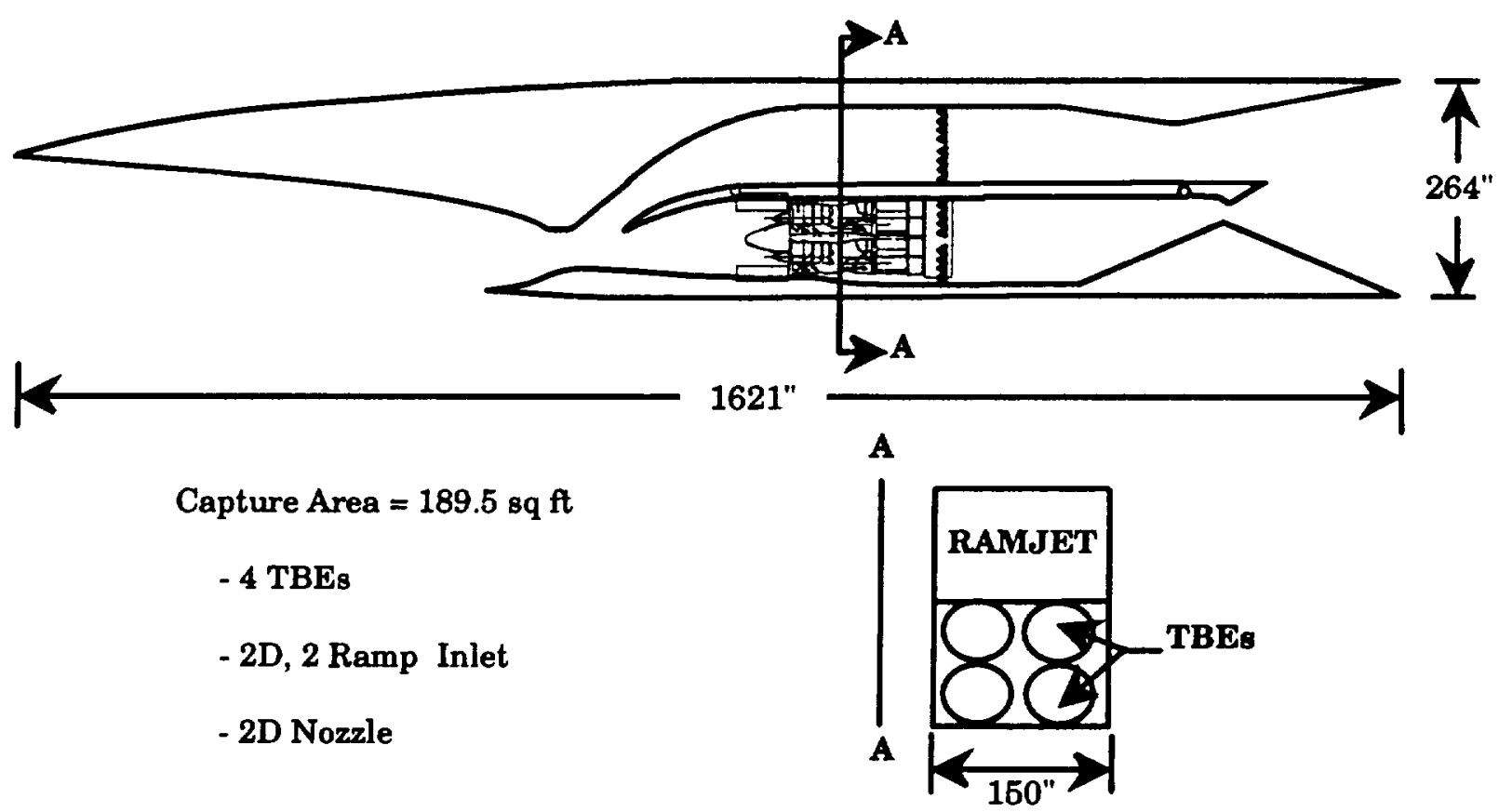

Figure 21. Beta II Propulsion Module

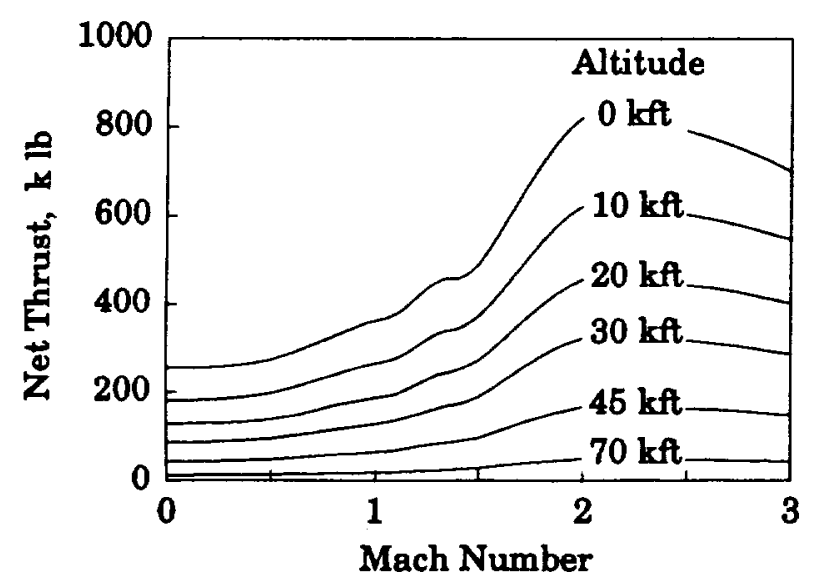

Figure 22. TBE Installed

Net Thrust

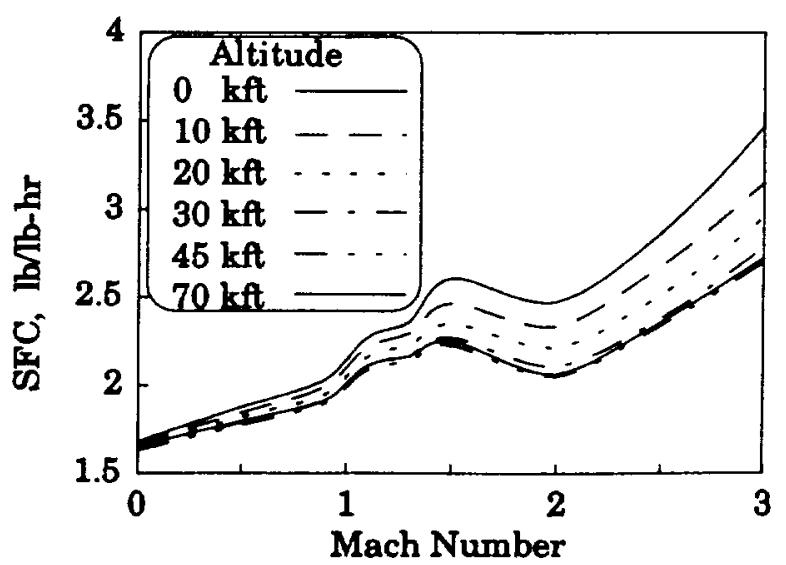

Figure 23. TBE Installed Specific Fuel Consumption (SFC) 


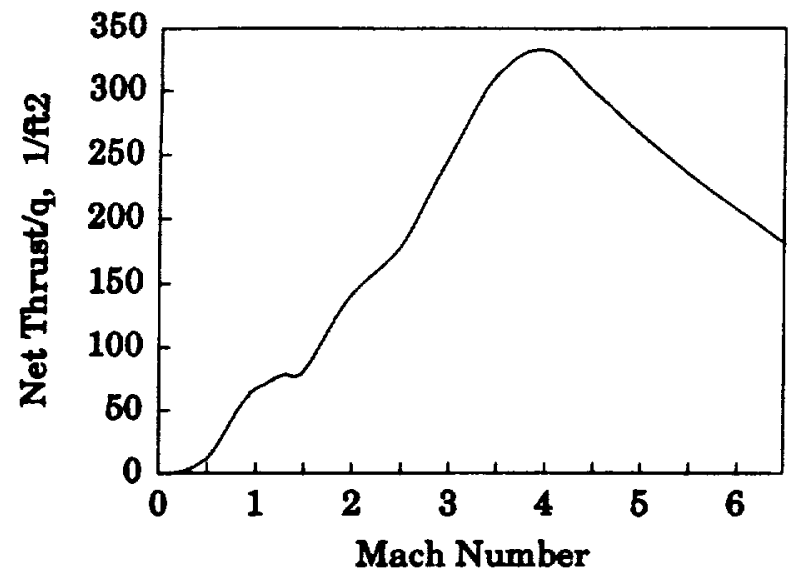

Figure 24. Ramjet Installed Net Thrust/q

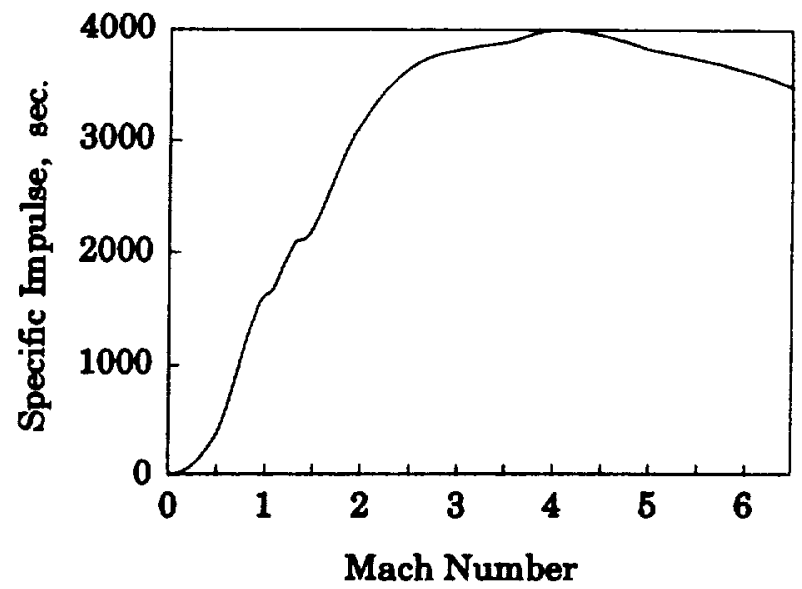

Figure 25. Ramjet Installed Specific Impulse 


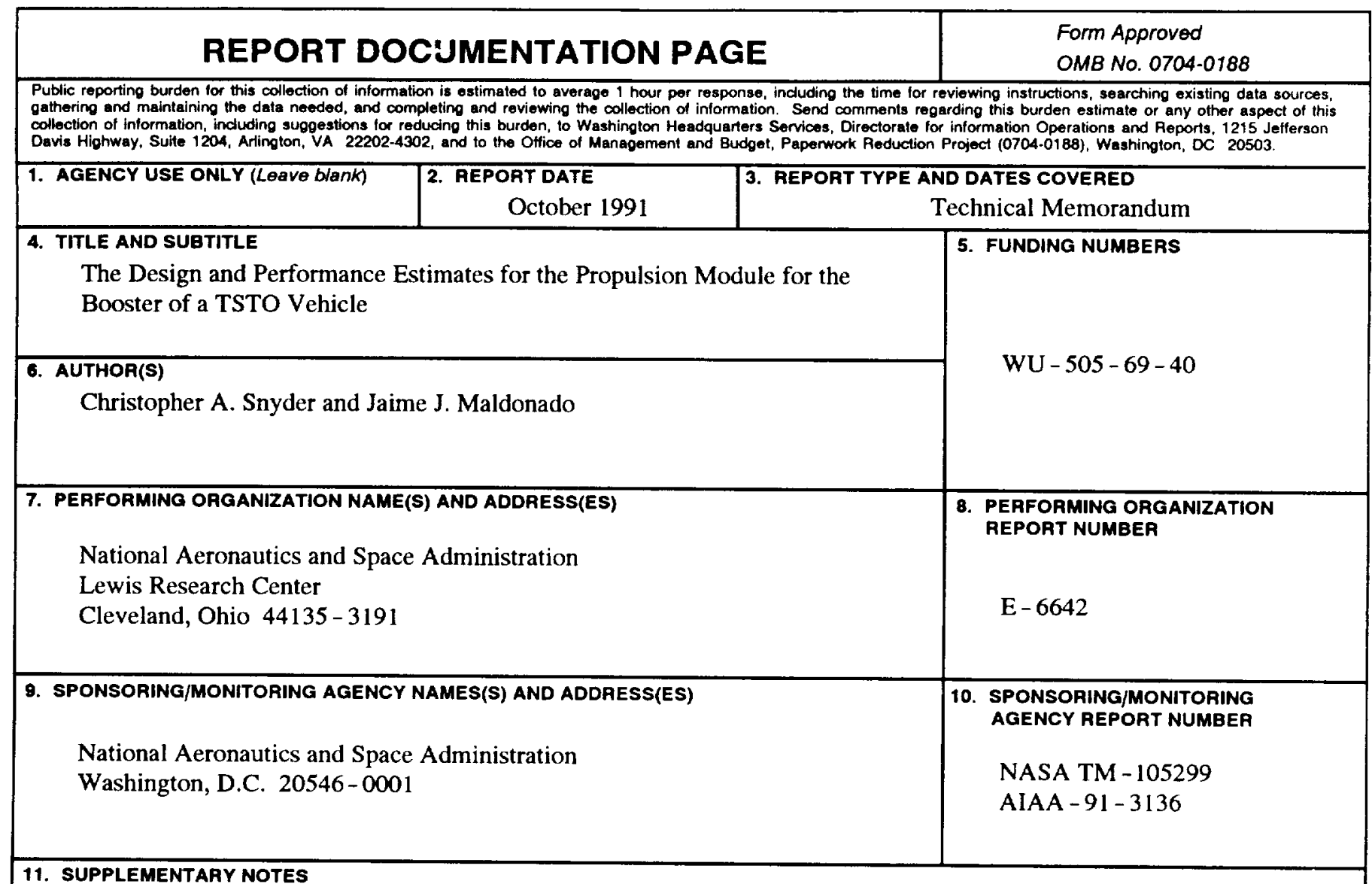

Prepared for the Aircraft Design Systems and Operations Meeting cosponsored by AIAA, AHS, and ASEE, Baltimore, Maryland, September 23 - 25, 1991. Responsible person, Christopher A. Snyder, (216) 977 - 7018.

12.. DISTRIBUTION/AVAILABILITY STATEMENT

12b. DISTRIBUTION CODE

Unclassified - Unlimited

Subject Category 07

13. ABSTRACT (Maximum 200 words)

The Aeropropulsion Analysis Office of the NASA Lewis Research Center is presently studying propulsion systems for possible low-risk replacements for the space shuttle. This study focussed its work on a smaller version of an Air Force two-stage-to-orbit (TSTO) concept called Beta. The NASA concept, Beta II, is to deliver 10,000 pounds to low polar orbit. (The original Beta vehicle is sized to delivered 50,000 pounds.) The booster stage requires a propulsion system for acceleration from take-off to the staging point of Mach 6.5 and about 100,000 feet altitude. The Beta II booster engine module consists of a unique over/under turbine bypass engine/ramjet engine configuration. Performance tradeoffs were required to integrate the inlet, turbomachinery, and ramjet design and operation. Discussions about these components and their interactions are included. The methodology and constraints used in the module layout and design will also be discussed. Propulsion system weight and performance will be presented along with preliminary mission study results of vehicle size.

\section{PRECEDING PAGE BLANKK NOT FILMEO}

14. SUBJECT TERMS

Air breathing engines; Transatmospheric vehicles; Gas turbine engines; Ramjet engines; Air breathing boosters; Aerospace planes

17. SECURITY CLASSIFICATION
OF REPORT
Unclassified
18. SECURITY CLASSIFICATION OF THIS PAGE Unclassified

19. SECURITY CLASSIFICATION OF ABSTRACT Unclassified 
